\title{
Blunt Cerebrovascular Injuries: Advances in Screening, Imaging, and Management Trends
}

W e would like to commend Nagpal et $\mathrm{al}^{1}$ for their study assessing the advances in screening, imaging, and management trends for blunt cerebrovascular injury (BCVI). However, we would like to point out a few persisting controversies regarding the management of patients with BCVI.

A major contributor to the confusion is the technique used for the diagnosis of BCVI. DSA has historically been the criterion standard. Increasingly, its use has been supplanted by CTA. However, the current role of DSA is not well-defined. Some groups recommend DSA for patients with negative CTA findings and persistent concern for BCVI, while other groups recommend DSA for patients with positive CTA findings. Paulus et $\mathrm{al}^{2}$ justified CTA use despite showing only $68 \%$ sensitivity (and 92\% specificity) for 64-channel multidetector CTA and recommended DSA for patients with CTA with negative findings with persistent neurologic symptoms. Subsequently, high false-positive rates of up to 47.9\% have been reported with CTA, with the authors strongly recommending the use of DSA in all patients with positive findings on CTA with suspected BCVI to avoid unnecessary anticoagulation. ${ }^{3}$ A possible explanation for the high false-positive rates is that the radiologists were overcalling vascular injury because of initial studies showing low sensitivity, bringing into question the need for a radiology review process. Unfortunately, most of these studies did not review the reasons for the reported low sensitivity or high false-positivity. Previous studies have also shown a learning curve with intervention, which resulted in the improved sensitivity of CTA without an increase in false-positives. Greater awareness of BCVI, the grading of injury, and imaging pitfalls would help improve noninvasive imaging diagnosis.

The justification for DSA after positive CTA findings is to avoid anticoagulation in false-positive reads. However, the same groups that showed a high false-positive rate with CTA also showed the relative safety of antithrombotic therapy, even in patients with traumatic brain injury and solid organ injury. ${ }^{4}$

Ultimately, it is the incidence and, hopefully, the prevention of subsequent stroke that would determine the utility of imaging. The true incidence of stroke in patients with BCVI is not well- understood. This is partly because detection of BCVI is imperfect, and most studies on BCVI report only the hospital course of these patients and not long-term outcomes. Studies that do report postdischarge outcomes have reported that up to $75 \%$ of strokes in BCVI may occur before the diagnosis is made on imaging. ${ }^{5}$ This finding is important to recognize while discussing the role of imaging. For example, it would be interesting to know whether the patients with negative DSA findings and positive CTA findings have any strokes subsequently.

Optimized, selective CTA in high-risk populations may be the most cost-effective strategy for BCVI detection. ${ }^{6,7}$

\section{REFERENCES}

1. Nagpal P, Policeni BA, Bathla G, et al. Blunt cerebrovascular injuries: advances in screening, imaging, and management trends. AJNR Am J Neuroradiol 2017 Oct 12. [Epub ahead of print] CrossRef Medline

2. Paulus EM, Fabian TC, Savage SA, et al. Blunt cerebrovascular injury screening with 64-channel multidetector computed tomography: more slices finally cut it. J Trauma Acute Care Surg 2014;76:279-83; discussion 284-85 CrossRef Medline

3. Shahan CP, Magnotti LJ, Stickley SM, et al. A safe and effective management strategy for blunt cerebrovascular injury: avoiding unnecessary anticoagulation and eliminating stroke. J Trauma Acute Care Surg 2016;80:915-22 CrossRef Medline

4. Shahan CP, Magnotti LJ, McBeth PB, et al. Early antithrombotic therapy is safe and effective in patients with blunt cerebrovascular injury and solid organ injury or traumatic brain injury. J Trauma Acute Care Surg 2016;81:173-77 CrossRef Medline

5. DiCocco JM, Fabian TC, Emmett KP, et al. Functional outcomes following blunt cerebrovascular injury. J Trauma Acute Care Surg 2013; 74:955-60 CrossRef Medline

6. Malhotra A, Wu X, Kalra VB, et al. Screening for pediatric blunt cerebrovascular injury: review of literature and a cost-effectiveness analysis. J Pediatr Surg 2015;50:1751-57 CrossRef Medline

7. Malhotra A, Wu X, Kalra VB, et al. Evaluation for blunt cerebrovascular injury: review of the literature and a cost-effectiveness analysis. AJNR Am J Neuroradiol 2016;37:330-35 CrossRef Medline

(1D) A. Malhotra

(1) X. Wu

(D) K. Seifert

Department of Radiology and Biomedical Imaging Yale University School of Medicine New Haven, Connecticut 